\title{
Inside a volcano: the first three-dimensional map
}

\section{from R.S.J. Sparks}

KILAUEA volcANO, HAWAII, has long been regarded as about the most thoroughly documented and best understood active volcano on Earth. Since 1952, increasingly sophisticated instruments have been used at the Hawaiian Volcanological Observatory to record the ground deformation caused by swelling of the volcano before major eruptions and the seismicity brought about by basalt magma moving beneath the volcano. Every eruption has been carefully documented with the volumes, discharge rates and lava composition measured on an almost daily basis during periods of activity.

The research has culminated in a recent paper by a team of US Geological Survey scientists (Ryan, Koyanagi \& Fiske $J$. geophys. Res. 86; 7111, 1981), in which an analysis of all the geophysical and volcanological data from 1969 to 1974 is used to construct a three-dimensional model of the internal structure of Kilauea's magmatic reservoir and transport system. The period was a particularly eventful one with several eruptions at the summit and the formation of the Mauna Ulu shield volcano on the east rift zone.

A clear Plexiglass scale-model containing 18 depth levels at $1 \mathrm{~km}$ spacing was constructed, upon which well located seismic hypocentres were plotted. The seismic network at Kilauea enables most earthquake sources to be located to better than $600 \mathrm{~m}$ in both horizontal and vertical coordinates, and it is possible to distinguish between earthquakes induced by fracturing of rock by magma under high fluid pressure and those produced by dry cracking of rock. When the magmatic events are plotted and placed in the threedimensional model, the zones of active magma transport can be identified down to a depth of $18 \mathrm{~km}$. This is the first time that the three-dimensional structure of an active magma reservoir system has been defined.

The model reveals some fascinating features of the Kilauea plumbing system. A well defined central magma storage system or chamber is located beneath Kilauea summit caldera from 2 to $6 \mathrm{~km}$ depth. The top of the magma chamber is defined by an elliptical zone of seismic activity at the 1.1 to $2.6 \mathrm{~km}$ levels. The interval from 5.7 to $6.5 \mathrm{~km}$ depth is nearly aseismic and is believed to represent the floor of the storage chamber. Modeliing of the ground deformation of the volcano also confirms that the magma reservoir can be treated as a source of pressure at depths in the range of 2.5 to $4 \mathrm{~km}$ (Dieterich \& Decker J. geophys. Res. 80; 4094, 1975). The reservoir has a capacity of between 5 and $10 \mathrm{~km}^{3}$ of basalt magma and is envisaged as a plexus of

R.S.J. Sparks is in the Department of Earth Sciences, University of Cambridge. interconnected intrusions.

A primary conduit feeds magma from the upper mantle at $14.6 \mathrm{~km}$ into the base of the shallow-level storage system. The conduit has been defined by seismic events that cluster tightly at different levels, forming a columnar region with a vertical axis and elliptical horizontal crosssections. It is important to appreciate that this conduit cannot be a totally magmafilled pipe, but rather consists of "honeycombed magma-filled fracture zones with appreciable fluid-to-rock ratios", that is, a zone through which magma migrates along fractures to the summit reservoir. Over the past 30 years basalt magma has been transported through this system at a remarkable steady rate of $3 \mathrm{~m}^{3} \mathrm{~s}^{-1}$

A second shallow-level pipe in the upper part of the east rift zone has also been identified. The zone has been the site of many eruptions and a close connection has been established between deflation of the ground above the summit reservoir and flank eruptions on the rift. Magma can be fed from the base of the main reservoir up this secondary pipe to the east rift and, in addition, earthquakes define an intense zone of intrusion, named the east rift zone duct, which feeds magma down the east rift at depths of less than $2.0 \mathrm{~km}$. A dyke swarm is probably forming in this zone.
The new model of the plumbing system is of great importance in understanding the origin of the basaltic lavas of Hawaii. The detailed petrology and geochemistry of the lavas documented for every eruption since 1952 can now be tied in with a well constrained model of the reservoir and transport system. The variations in temperature and composition can be investigated with a good idea of where each batch of magma originates. For example, there is a general tendency for the east rift zone magma fed from the summit to be hotter than that erupted at the summit, consistent with diversion of hotter magma from the base of the summit reservoir or directly from the primary conduit below into the east rift zone pipe.

The modelling technique may also prove valuable in more productive monitoring and prediction of the volcano's behaviour. As more data are made available, the movement of magma within the volcano and changes in the reservoir and transport system can be observed. The study shows that there is no substitute for the continuous and year-by-year documentation of an active volcano. It is not just the authors of this paper who are to be congratulated for the success of the Hawaiian monitoring programme, but the many volcanologists working on Hawaii over more than 20 years.

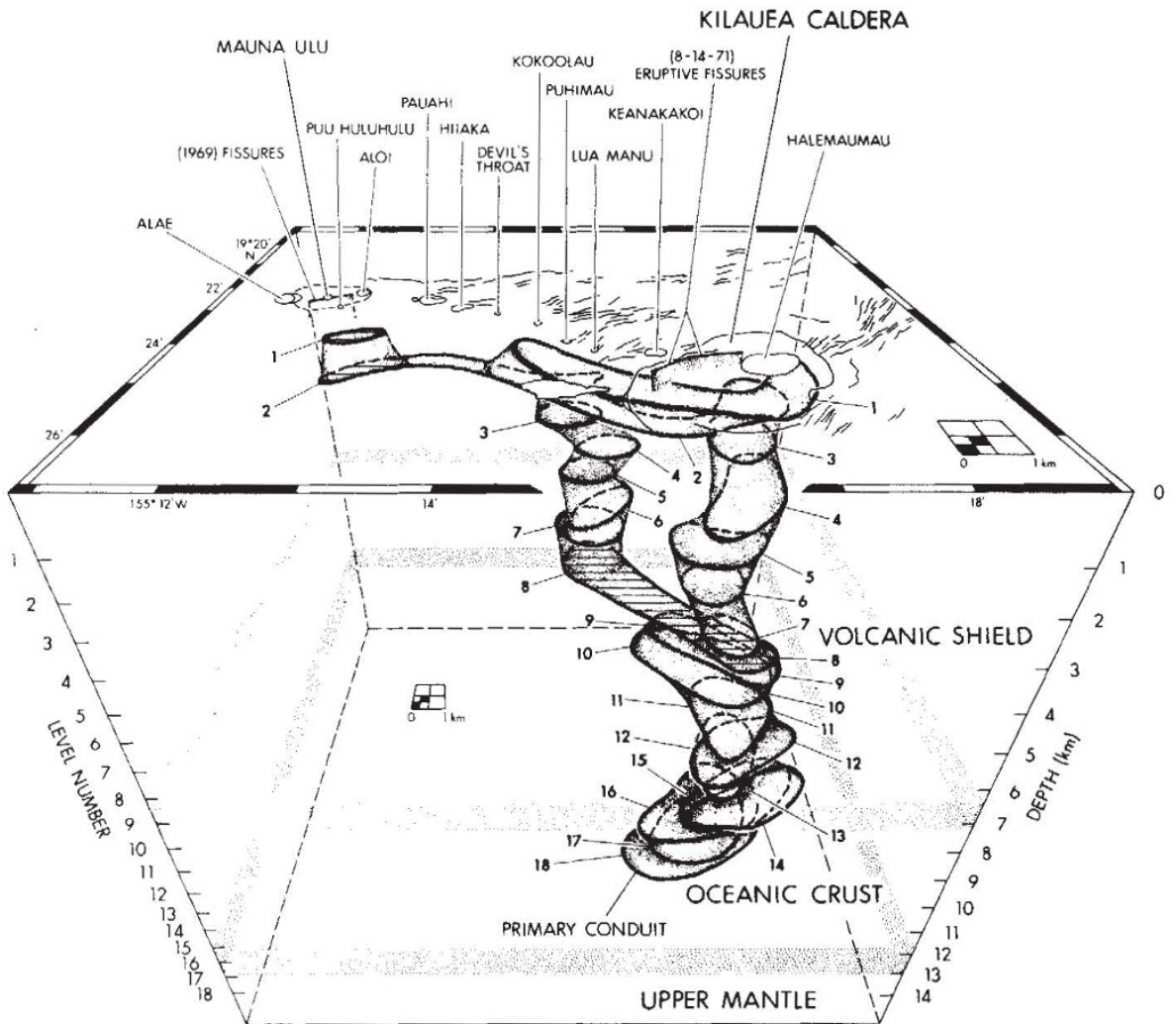

Southward view, looking down into the interior of Kilauea. The transition zones from volcanic shield to oceanic crust, and from oceanic crust to upper mantle are stippled. Square, $1 \mathrm{~km}$ scale grids are at the 0.0 and $14.7 \mathrm{~km}$ depth levels. 